\title{
VL51ES (Generation 6) LI-ION CELL FOR SATELLITES
}

\author{
Defer M. ${ }^{1}$, Borthomieu Y. ${ }^{1}$, Ligneel E. ${ }^{1}$, Badet S. ${ }^{2}$, Chocinski D. ${ }^{1}$ \\ ${ }^{1}$ Saft, Space and Defence Division, BP 1039, 86060 Poitiers - France,Email: david.chocinski@saftbatteries.com;
} mathieu.defer@saftbatteries.com; yannick.borthomieu@saftbatteries.com; eric.ligneel@saftbatteries.com

${ }^{2}$ Saft, 111 Bd A Daney, 33074 Bordeaux, Email: sebastien.badet@saftbatteries.com

\begin{abstract}
This paper presents the design of Saft's VL51ES (Generation 6) Li-Ion cell, the main challenges in the course of the development, the main BOL characteristics and performances achieved during the development program. Finally, it also describes how this cell fits in Saft's battery range and the benefits of it.
\end{abstract}

\section{INTRODUCTION}

Considering the long cell development and qualification cycle for space application, Saft decided in 2011 to start at its own expenses the development of G6 cells (VL51ES) with GEO application as primary target in order to take over G5 cells (VES180SA). The CDR was held in June 2015 and the cell qualification started in first trimester 2016.

While keeping cell mechanical, electrical and thermal interfaces as close as possible to G5 in order to ensure compatibility with current platforms, the main development axes taken into account were as follows:

- Upgrade to industrial and cost-effective solutions (tab less, radial welds, can, metallic winding mandrel, terminals, axial holding...);

- Improvement of performances compare to G5;

- Enlargement of specifications to lower scraps where it makes sense.

The challenge was to reuse as much as possible the materials and parts, the designs and processes used for industrial applications often bringing cost reductions while seeking to ensure equivalent level of product quality, performance and robustness as current space G5 cells.

The qualification of two 2 manufacturing plants (one in France and one in US) was included in the scope for capacity back-up and to address markets locally. They will fulfill ESA ECSS normative referential with same level of demonstration as for G5 cell qualification in the frame of Artes8 program.

In addition, another main topic was to select appropriate design for adequate tightness of the cell life long and validate it by representative wear out tests.

Finally, in parallel to VL51ES cell development, the validation of the associated modules designs and processes in head up and head down configurations is conducted to assess feasibility of battery designs with the new cell, and conduct a qualification in module configuration mechanically and thermally representative of the final application.

\section{MECHANICAL ASPECTS}

\subsection{General Design}

VL51ES space cell design combines Saft space reliability and a maximum of regular industrial processes.

In order to maintain as far as possible current satellite battery design, the VL51ES cell dimensions (Figure 1) are close to the one of the current VES180SA space cell.

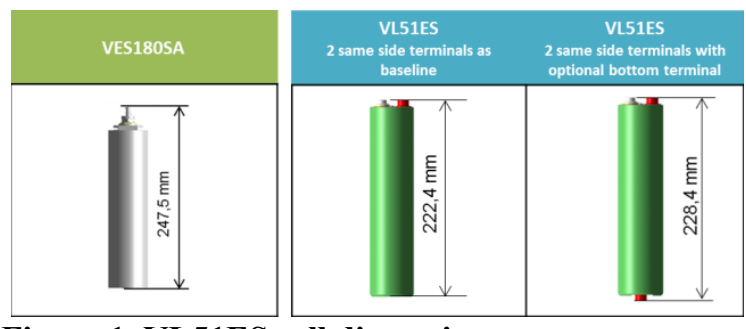

Figure 1. VL51ES cell dimensions

VL51ES cell can have the power connections on the same side (top side) or on opposite side by the 
addition of a specific positive terminal on the bottom of the cell (Figure 2).
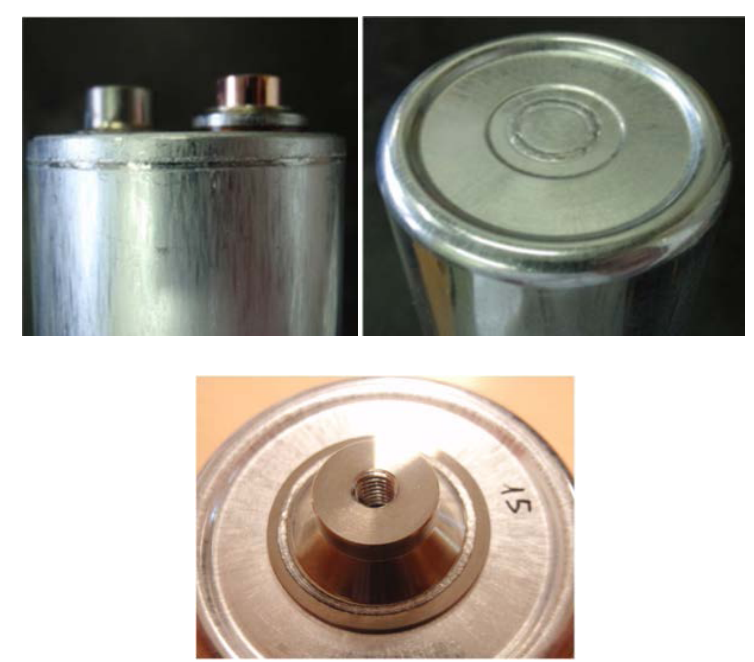

Figure 2. VL51ES Li-ion cell mechanical envelop

\subsection{Internal design: Tabless and Jelly roll holding designs}

As mentioned previously, in order to be close to the industrial cell road map, VL51ES cell design applies industrial cell heritage for some design key points: The tab less and the jelly roll holding designs.

The advantages of the tabless design are:

- More robust and reproducible

- More easy to produce

- Less scraps

- More reliable

In VES180SA cells the jelly roll is hold in position, axially, by only screwing it in the positive cover.

For VL51ES cell, jelly roll and electrode collectors are axially held in position, by means of shims on both positive and negative sides.

Therefore, contrary to VES180SA cell, jelly roll adjustement radially in diameter is not required due to axial holding.

The pros and con of the industrial jelly roll holding design vs. current VES180SA design are the following (Table 1):

\begin{tabular}{|l|l|}
\hline \multicolumn{1}{|c|}{ VL51ES cell } & \multicolumn{1}{c|}{ VES180SA cell } \\
\hline Pros & Pros \\
\hline $\begin{array}{l}\text { Design close to } \\
\text { industrial cell }\end{array}$ & $\begin{array}{l}\text { Jelly roll diameter is } \\
\text { maximized }\end{array}$ \\
\hline $\begin{array}{l}\text { Low stress through } \\
\text { internal electrical } \\
\text { connection due to design }\end{array}$ & $\begin{array}{l}\text { Proven } \\
\text { regarding mechanical } \\
\text { environments }\end{array}$ \\
\hline Cons & Cons \\
\hline $\begin{array}{l}\text { Chain of dimension to be } \\
\text { mastered axially }\end{array}$ & $\begin{array}{l}\text { Manual labor spent for } \\
\text { jelly roll dimensional } \\
\text { adjustement on cell can } \\
\text { (just slipping process) }\end{array}$ \\
\hline
\end{tabular}

Table 1. Jelly roll holding advantages and disadvantages

\subsection{Mechanical validation}

The challenge behind was to study and validate the use of such solutions for space applications.

Proof of mechanical concept was performed on preliminary Engineering Model (EM) prototypes including both vibrations and shocks tests campaigns.

Then EM and Qualification Model (QM) prototype cells were mechanically tested in battery structures. The tested cells included specific worst cases representative of design and process limits. They were selected or manufactured depending on:

- The gap between the jelly roll (which is not adjusted) and the can, and also depending on the axial holding

- The axial compression due to the shims and the jelly roll edge folding induced by the tabless design.

QM cells were already succesfully submitted to the following tests:

\section{- Standard Vibration test}

For sine vibration, the following profile was applied with cell EOCV between $3.85 \mathrm{~V}$ and $3.9 \mathrm{~V}$.

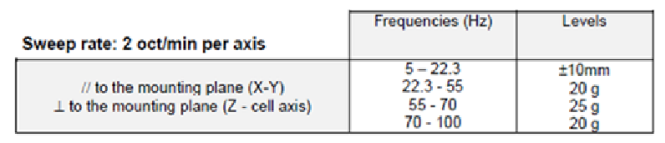

Table 2. Sine vibration profile 
For random vibration, the following profile was applied with cell EOCV between $3.85 \mathrm{~V}$ and $3.9 \mathrm{~V}$.

\begin{tabular}{|c|c|c|c|}
\hline \multicolumn{4}{|c|}{ Random vibe } \\
\hline \multicolumn{4}{|c|}{ Duration: 3 minutes per axis } \\
\hline Oz (perpendicular, cell axis) & OxOy (parallel to mounting plane) \\
\hline Frequency & Level & Frequency & Level \\
$(\mathrm{Hz})$ & $\left(\mathrm{g}^{2} / \mathrm{Hz}\right)$ & $(\mathrm{Hz})$ & 0.025 \\
\hline 20 & 0.092 & 20 & 0.1 \\
$65-400$ & 0.3 & $00-1000$ & 0.05 \\
200 & 0.06 & 2000 & 0.05 \\
\hline \multicolumn{2}{|c|}{ Global = $17.39 \mathrm{gRMS}$} & \multicolumn{2}{|c|}{ Global $=12.85 \mathrm{gRMS}$} \\
\hline
\end{tabular}

Table 3. Random vibration profile

- Shock test

The following shock levels were applied depending on the cella axis. Cell state of charge is at $40 \%$.

\begin{tabular}{|c|c|c|}
\hline 3 times per axis along a unique & & \\
direction & Frequencies $(\mathrm{Hz})$ & Levels $(\mathrm{g})$ \\
\hline \multirow{3}{*}{$\perp$ to the mounting plane $(\mathrm{Z})$} & 100 & 60 \\
\cline { 2 - 3 } & 1000 & 1000 \\
\cline { 2 - 3 } & 2700 & 2150 \\
\hline \multirow{2}{*}{$\begin{array}{c}\text { 3 times per axis along a } \\
\text { unique direction }\end{array}$} & 10000 & 2150 \\
\hline \multirow{3}{*}{$/ /$ to the mounting plane $(X-Y)$} & 100 & 60 \\
\cline { 2 - 3 } & 1000 & 1000 \\
\cline { 2 - 3 } & 2000 & 2000 \\
\hline
\end{tabular}

Table 4. Shock test levels for each axis

\section{- Constant acceleration}

The success criteria of these tests are established by taking care of ECSS requirements and customers product specifications.

In parallel to these tests, mechanical margins are being evaluated by finite element analysis with material properties and load cases defined from theoretical studies and/or by tests taking into account the internal pressure built-up and jelly roll swelling life long linked to ageing, cycling and irradiation.

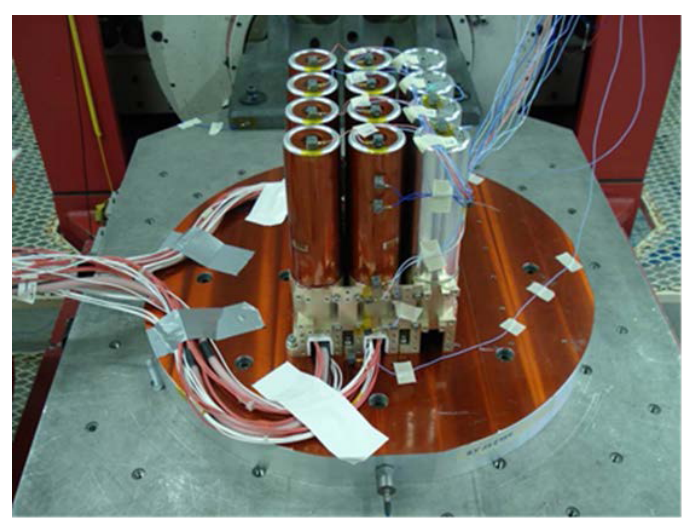

Figure 3. 3S4P VL51ES module for mechanical tests

\section{CELL PERFORMANCES}

\subsection{Generality}

VL51ES electrochemistry was chosen by considering several aspects:

\subsubsection{Supplying aspect}

As far as possible, the electrode components must be available during all the cell life manufacturing and in synergy with industrial cell roadmap. A small material change in the cell definition will lead to time consuming cell delta qualification. A preliminary study of the supplier robustness was performed and gave orientation to the active materials to use in VL51ES cell.

\subsubsection{Heritage aspect}

VL51ES electrochemical design cell was established according to the heritage acquired on the current industrial cell. The electrochemistry is based on a NCA/Graphite technology which is flightworthy and has already demonstrated good cycling and calendar life characteristics.

\subsubsection{Specific ernergy improvement vs. VES180SA cells}

A lot of work was done to increase the cell specific energy by working on the optimization of the cell electrode design with a specific focus on the electrode porosity, electrode loading, the thickness of the separator and of the foils. In that we were able to reach an average specific energy of $\sim 170 \mathrm{Wh} / \mathrm{kg}$ at $4.1 \mathrm{~V}$, charge $\mathrm{C} / 10$, discharge $\mathrm{C} / 2$ compared to 155 $\mathrm{Wh} / \mathrm{kg}$ for VES180SA cell. This kind of modification induced a lot of impacts that were handled at product and process level.

\subsection{QM cells characteristics}

The main contributors to the cell specific energy increase are the thicknesses of the foils and of the separator.

The chosen electrode design on QM cells is a compromise between initial performances, supplier materials availability and expected cycling durability. The chosen active materials were processed in order to be similar in term of raw energy to VES180SA cell characteristics. 


\subsubsection{Standard characteristics}

The first electrical tests on QM VL51ES cell give the following data (Table 2):

\begin{tabular}{|l|c|c|}
\cline { 2 - 3 } \multicolumn{1}{c|}{} & VES180SA & VL51ES (QM) \\
\hline Average capacity (Ah) @ 4,1 V & 49,4 & 51 \\
\hline Average energy (Wh) @4,1 V & 178 & 182 \\
\hline Average mass (g) & 1128 & 1076 \\
\hline Average specific energy (Wh/kg) & 158 & 169 \\
\hline Voltage range & \multicolumn{2}{|c|}{$2,7 \mathrm{~V}-4,1 \mathrm{~V}$} \\
\hline Internal resistance (m $\Omega$ ) & \multicolumn{2}{|c|}{$<2,5$} \\
\hline Temperature & \multicolumn{2}{|c|}{$+10^{\circ} \mathrm{C}-+60^{\circ} \mathrm{C}$} \\
\hline
\end{tabular}

Table 5. VES180SA and VL51ES cell characteristics

These results are in line with the VL51ES cell specification.

\subsubsection{Cell energy for various EOCV}

Cells energy was evaluated for various SOC. The data are reported on Figure 4. The behavior is typical for a NCA based positive active material.

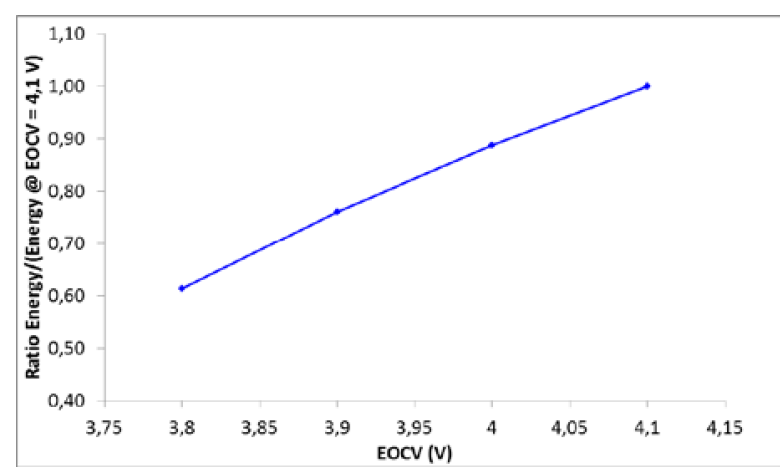

Figure 4. Cell energy ratio depending on EOCV

\subsubsection{Cell energy for various temperatures}

Cells were characterized at : $+0^{\circ} \mathrm{C},+10^{\circ} \mathrm{C},+20^{\circ} \mathrm{C}$, $+30^{\circ} \mathrm{C},+40^{\circ} \mathrm{C}$, and $+55^{\circ} \mathrm{C}$ at $\mathrm{D} / 2$. The data are reported on Figure 5.

At $+0^{\circ} \mathrm{C}$, the cell can delivered $85 \%$ of the reference energy at $+20^{\circ} \mathrm{C}$. Discharge energy is gained by using the cell up to $+40^{\circ} \mathrm{C}$. Above $+40^{\circ} \mathrm{C}$, the gain is not significative.

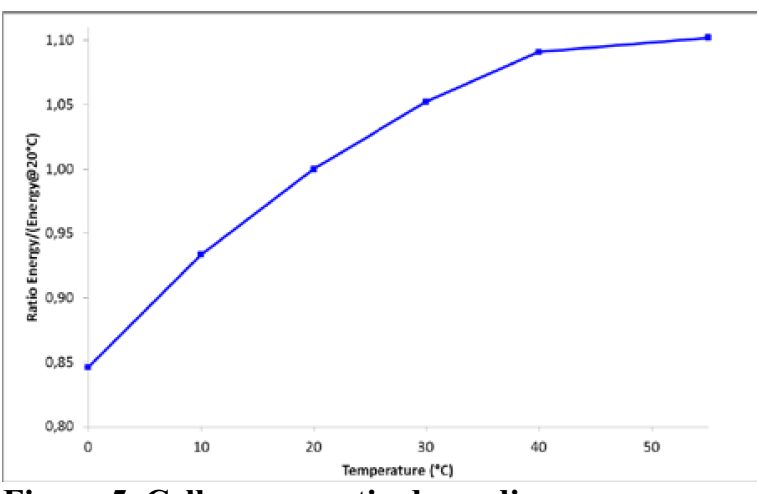

Figure 5. Cell energy ratio depending on temperature

\subsubsection{Cell energy for various discharge powers}

At $+20^{\circ} \mathrm{C}$, cells were characterized for the following discharge powers: $45 \mathrm{~W}, 90 \mathrm{~W}, 120 \mathrm{~W}$, and $180 \mathrm{~W}$.

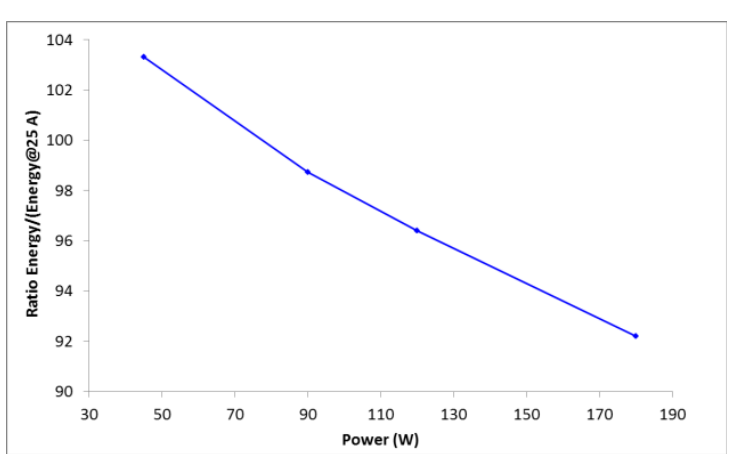

Figure 6. Cell energy ratio depending on discharge power

As usual, the delivered energy decrease when we increase the discharge power. At $1 \mathrm{C}$, the cell delivers $92 \%$ of the discharge energy measured at $\mathrm{D} / 2$.

\subsubsection{Self discharge characterization}

At $+20^{\circ} \mathrm{C}$, cell self discharge was mesasured over 3 months for an open charge voltage of $3.9 \mathrm{~V}$. The voltage data are reported on Figure 7. 


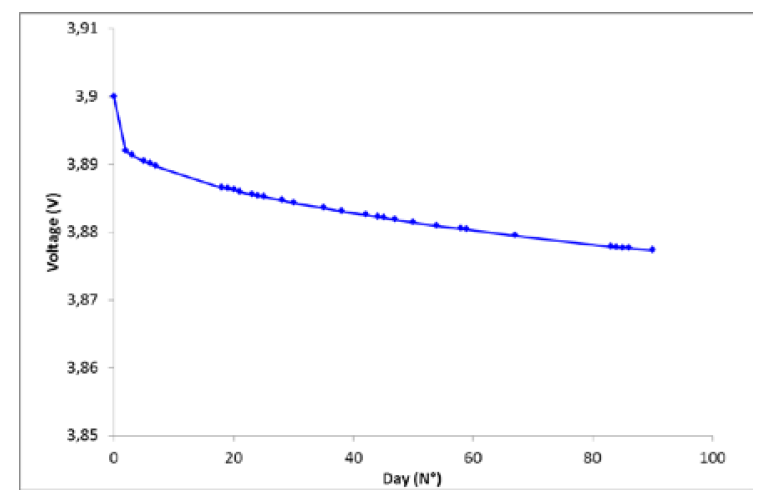

Figure 7. Cell voltage evolution over 3 months

Over 90 days the voltage drop is less than 0.2 $\mathrm{mV} /$ day. This represent less than 5\% energy drop over this period.

\subsection{Cell durability}

\subsubsection{Nominal cell cycling performances}

The validation tests campaign is in progress on EM and QM cells to evaluate the specific energy End of Life. It includes, GEO accelerated testing with and without solstice, calendar life tests at different temperatures with pressure sensors, as well as irradiation with pressure sensors. The results will be compared to results obtained on VES180SA cell.

The expected cell cycling performance are the following:

- Cell energy at end of life over $160 \mathrm{Wh}$ after 19 years GEO cycling at $80 \%$ DoD. EM and QM results are currently compliant after 20 seasons on EM and 8 seasons on QM.

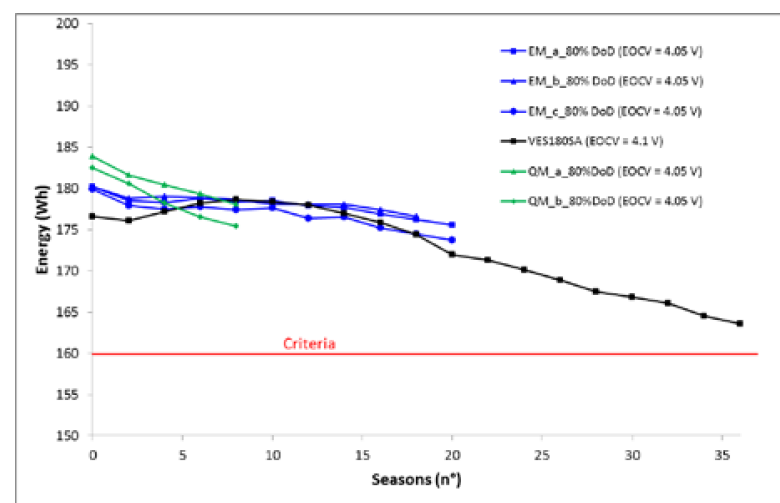

Figure 8. VES180SA and VL51ES cell energies in accelerated GEO cycling at $80 \%$ DoD without solstice
The corresponding accelerated GEO cycling profile without solstice is reported on Figure 9.

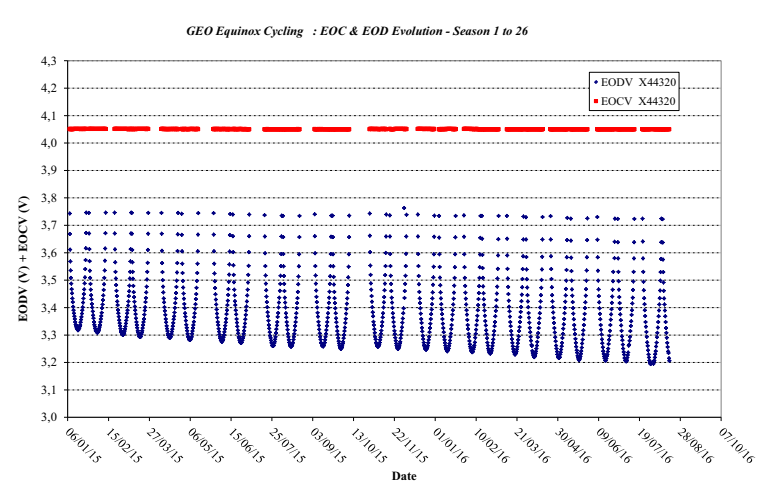

Figure 9. Accelerated GEO cycle profile without solstice (maximum $80 \%$ DoD)

For EM cells, End Of Discharge Voltages for the deepest discharge per season are reported on Figure 10. We have an identical behavior between VES180SA and VL51ES. The criteria which is $\mathrm{EODV} \geq 3.14 \mathrm{~V}$ at 32 seasons is currently fulfilled.

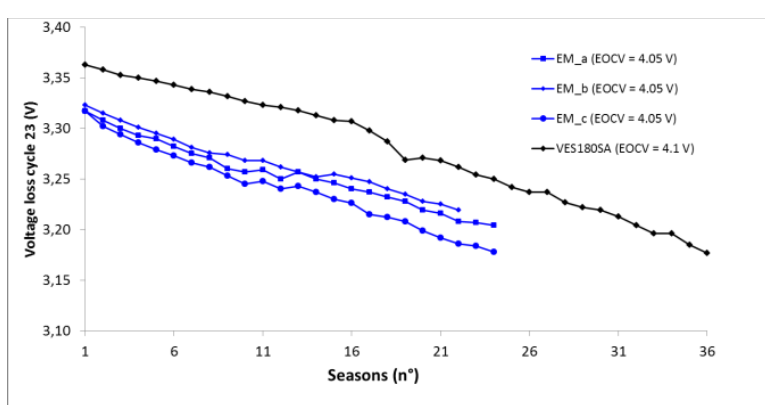

Figure 10. EODV at $80 \%$ DoD depending on cycle number during accelerated GEO cycling without solstice

- Cell pressure below 6.89 bars at the cell end of life (not pressure vessel) with an irradiation dose compatible with space applications. A calendar test at $60^{\circ} \mathrm{C}$ at $\mathrm{OCV}=4.1 \mathrm{~V}$ on a cell equipped of pressure sensor is currently in progress. The results will be correlated with the cell pressure model. In parallel some cells equipped of pressure sensor are irradiated up to $8 \mathrm{Mrad}$ in order to established the cell internal pressure increase depending on the irradiation rate.

In order to fit with new generation full electric satellites, QM VL51ES cell are tested by taking care of solicitations due to the satellite plasmic propulsion systems. The cycling test profils have been adapted depending on the customer specifications. 


\subsubsection{Cell process validation}

The cell electrode manufacturing processes and treatments have slight differences between manufacturing plants and present some tolerances on parameters (electrode porosity, loading and thickness).

Therefore, sensitivity and limit studies are conducted to optimize these processes.

Specific EM \& QM cells were manufactured and tested to cover worst cases. Moreover different types of filling, impregnation and formation processes were evaluated to achieve the best compromise in term of cell performance and cell processability.

\section{CELL IMPLEMENTATION}

\subsection{Cell pack characteristics}

VL51ES cell interface was developed in order to be plug \& play in the current Saft cell pack structure in head down or head up configurations.

Compare to a standard VES180SA cell pack, VL51ES cell pack will present:

- Lower weight

- Lower height

In addition, preliminary thermal tests and modelling did not show significant different thermal characteristics between a VES180SA cell pack and a VL51ES cell pack.

\subsection{Preliminary cell pack validation}

At QM level, the cell in battery configuration will be thermally tested by thermal vaccum tests confirming the thermal characteristic of a cell pack. Currently in progress, the results are expected in second trimester 2016.

\subsection{Battery range}

Based on the EM and QM cell design, a battery range started to be evaluated and compared to the current VES180SA battery range.
On the table, we reported the benefit in mass and in energy to use VL51ES (G6) cells instead of VES180SA (G5) cells in (20S to 24S)-XP batteries.

\begin{tabular}{|c|c|c|}
\hline & $\begin{array}{c}\text { Battery Power Benefit } \\
\text { G6 vs G5 (kW) }\end{array}$ & $\begin{array}{c}\text { Battery Mass Reduction } \\
\text { G6 vs G5 (kg) }\end{array}$ \\
\cline { 2 - 3 } & Average & Average \\
\hline 2P Battery & 0.3 & -2.5 \\
\hline 3P Battery & 0.5 & -3.7 \\
\hline 4P Battery & 0.7 & -4.9 \\
\hline 5P Battery & 0.8 & -6.2 \\
\hline 2*3P Dual Battery & 1.0 & -7.4 \\
\hline 2*4P Dual Battery & 1.3 & -9.9 \\
\hline 2*5P Dual Battery & 1.7 & -12.3 \\
\hline
\end{tabular}

Table 6. Benefit of VL51ES (G6) cell batteries vs. VES180SA (G5) batteries (20S to 24S structures)

The benefits are significant for large batteries.

A battery development range is started for NEOSAT program with VL51ES cells.

\section{CONCLUSIONS AND FUTURE WORK}

The electrochemical and mechanical designs of Saft's VL51ES Li-Ion cell were finalized in third trimester 2015. QM cells were built and have started tests. The first electrical and mechanical results are satisfactory. Beginning of life Qualification Review is expected in late October 2016.

\section{REFERENCES}

[1] Y. Wang, J. Jiang, J.R. Dahn, Electrochemistry Comm., 9, 2534 (2007)

[2] K. Shizuka, C. Kiyohare, K. Shima, Y. takeda, J. Power Sources, 166, 233 (2007)

[3] Julien Bréger, thèse "Combined NMR and PDF Studies of Positive Electrode Materials for Rechargeable Li-ion Batteries" (2006)

[4] Z. Lu, L.Y. Beaulieu, R.A. Donaberger, C.L. Thomas, J.R. Dahn, J. Electrochemical Soc., 149 [6], A778 (2002)

[5] Z. Lu, J.R. Dahn, J. Electrochemical Soc., 149 [7], A815 (2002)

[6] J.-H. Kim, Y.-K. Sun, J. Power Sources, 119121, 166 (2003)

[7] J. Jiang, J.R. Dahn, Electrochimica Acta, 50, 4778 (2005) 